\title{
Evaluation of Malondialdehyde in Type 2 Diabetes Mellitus Patients as Oxidative Stress Markers in Bengkulu Population
}

\author{
Raden Sunita ${ }^{1 *}$, Sahidan Sahidan ${ }^{1}$, Rachmat Hidayat ${ }^{2}$ \\ ${ }^{1}$ Polytechnic of Health,Bengkulu, Indonesia \\ ${ }^{2}$ Department of Biology, Faculty of Medicine, Universitas Sriwijaya, Indonesia \\ \#Correspondence Author Email : $\underline{\text { sunita@gmail.com }}$
}

\begin{abstract}
Introduction.Hyperglycemia in Type 2 Diabetes Mellitus (T2DM) can cause individuals to experience oxidative stress conditions, accompanied by a decrease in antioxidant activity in protecting cellular components against the attack of reactive oxygen species (ROS). ROS oxidized lipid components can produce Malondialdehyde (MDA). Evaluation of MDA can be used as a marker Oxidative stress which can indirectly describe the effects of ROS because ROS compounds are reactive. This study aims to determine the analysis of MDA in T2DM subjects at the Sentinel Public Health Center in Bengkulu City in 2017.
\end{abstract}

Methods.Research Analytic with a case control study design in 40 samples of T2DM subjects (cases) and 40 Non-DM samples (control) were carried out at the Sentinel DM Health Center in Bengkulu City. Data collection used questionnaires, measurements of Body Mass Index, examination of Fasting Blood Glucose and plasma MDA (spectrophotometry).

Results. The results of this study there were differences in characteristics (Gender, Age, BMI, Blood Pressure, Fasting Blood Glucose) in subjects with T2DM and Non-T2DM in the Bengkulu City Sentinel Health Center in 2017 (p <0,000). There was a significant difference $(p=0,000)$ in higher MDA levels in patients with T2DM than non-DM subjects. The MDA frequency distribution in the case was MDNormal (24\%) and MDA Normal (6\%), whereas in the control was MDA Not Normal (26\%) and MDA Normal (44\%). There were significant differences in MDA frequency distribution between cases and controls $(p=0,000)$. The subjects of T2DM had a risk of 6.77 times an increase in MDA levels compared to NonDMT2 ( $p=0.000$, OR 6.77 IK 95\% 2.44-18.73). The correlation between levels of GDP and MDA was statistically significant $(\mathrm{p}<0.001)$ with a positive correlation direction $(0.340)$.

Conclusion.The results of this study are expected to be used as a basis for the development of individual therapy in subjects with T2DM in order to prevent the occurrence of complications early on. 
Keywords:plasma malondialdehyde, fasting blood glucose, T2DM

\section{Introduction}

Diabetes as a chronic disease that requires multifactorial risk reduction strategies. The increasing incidence of type 2 diabetes mellitus (T2DM) is a metabolic disease characterized by hyperglycemia due to damage to insulin secretion, insulin action and / or both. ${ }^{1}$ Estimates of DM patients in 2035 show that there are 347 million people living in urban areas and around 145 million people living in rural areas. $^{2}$ Without effective management and prevention programs, the prevalence and complications of DM will continue to increase in the world. DM complications are associated with long-term damage, dysfunction and disturbances in the organ systems which are initiated by blood vessel damage which is characterized by an increased risk of macrovascular and microvascular complications. ${ }^{3,4}$

Type 2 diabetes mellitus (T2DM) with the highest prevalence of around $90-95 \%$ of all DM cases, is a metabolic disease characterized by chronic hyperglycemia and abnormal metabolism of carbohydrates, proteins and lipids due to disorders of insulin secretion, insulin action, or both, which contribute to oxidative stress and inflammatory processes. ${ }^{5-7}$ Hyperglycemia causes oxidative stress in T2DM through several mechanisms, including glucose autoxidation, nonenzymatic protein replication, polyol pathway activation, glycolysis pathway and pentose phosphate pathway. ${ }^{8-11}$ Oxidative stress occurs due to decreased concentration or antioxidant activity and increased production of free radicals reactive oxygen species. ${ }^{12}$

Reactive oxygen species (ROS) are highly reactive and have a long life span so they can attack, modify and damage all cellular biomolecules, including deoxyribonucleic acid (DNA), ribonucleic acid (RNA), carbohydrates, proteins, and membrane lipids. ${ }^{13,14}$ These biomolecular products oxidized by ROS are often used as markers to detect oxidative stress activity in cells. The interaction of ROS with membrane lipids causes and increases lipid peroxidation which results in the formation of aldehydes with reactive terminal carbonyl groups such as acrolein, and malondialdehyde (MDA). ${ }^{15,16}$ Increased MDA concentrations are reported with increasing plasma glucose levels and duration of suffering from DM, as well as in inflammatory conditions. ${ }^{17,18}$ Increased MDA levels can alter the integrity of the cell membrane structure, trigger cell damage, and cause the release of proinflammatory mediators. ${ }^{19,20}$ This is because MDA can modify or denaturate several functional groups of 
protein and DNA, which are the initial stages of inflammation mediated by oxidative stress. $^{21,22}$

\section{Methods}

This study used a case-control study design with a case-control study design involving as many as 100 samples from the Sentinel DMT2 Health Center, which were collected according to the inclusion and exclusion criteria to be determined as the subject of the study, especially based on the results of screening of fasting blood glucose levels (GDP), so that the control group (GDP <126 mg / dL) was obtained, amounting to 50 healthy subjects with no history of DM (non-DM) and case groups (GDP $\geq 126 \mathrm{mg} / \mathrm{dL}$ ) consisting of $50 \mathrm{~T} 2 \mathrm{DM}$ subjects.

GDP levels were analyzed by spectrophotometry method of glucose oxydase-p-amino phenazone (GOD-PAP) and the level of lipid peroxidation was determined by examination of malondialdehyde (MDA) using a modifiedmethod thiobarbituric acid reactive substances (TBARS). The working principle of this method is based on Knoevenagel type condensation reaction, namely the reaction of one MDA molecule with 2 molecules of 2-tiobarbiturate acid under acidic conditions (low $\mathrm{pH}$ ) and high temperature, which will release 2 water molecules with the formation of MDA-complex (TBA) as a pink chromophore called thiobarbituric acid reactive substances (TBARS), which was measured at a maximum absorbance of 532 $\mathrm{nm}$ using a spectrophotometer.

\section{Results}

Table 1 shows the characteristics of cases and controls. Characteristics of the study subjects were tabulated into three characteristics, namely variables (including gender, age, BMI, blood pressure and GDP), control group (non-DM) and T2DM group, while the data values of each characteristic were presented in categorical form (number and percentage ) and continuous form (median, minimum-maximum andvalue $p$ ).

Table 1. Characteristics of Research Subjects

\begin{tabular}{lccr}
\hline \multirow{2}{*}{ Variables } & \multicolumn{2}{c}{ Group } \\
\cline { 2 - 3 } & Control $(\mathrm{n}=50)$ & Cases $(\mathrm{n}=50)$ & Value $p$ \\
\hline gender & $4(8.0 \%)$ & $14(28.0 \%)$ & - \\
Male $(\%)$ & $46(92.0 \%)$ & $36(72.0 \%)$ & - \\
\hline
\end{tabular}




\begin{tabular}{|c|c|c|c|}
\hline Age (years)* & $48(26-77)$ & $53(17-78)$ & $0,000^{*}$ \\
\hline Weight (kg) & $53(42-67)$ & $62(50-84)$ & \\
\hline Height (m) & $1.53(1.41-1.68)$ & $1.55(1.47-1.67)$ & \\
\hline BMI $\left(\mathrm{kg} / \mathrm{m}^{2}\right)$ & $23.14(18.67-24.78)$ & $2548(19.95-36.36)$ & $0,000^{*}$ \\
\hline \multicolumn{4}{|l|}{ blood } \\
\hline $\begin{array}{l}\text { Systolicpressure } \\
(\mathrm{mmHg})\end{array}$ & $115(90-140)$ & $120(100-160)$ & $0,000^{*}$ \\
\hline Diastolic $(\mathrm{mmHg})^{*}$ & $80(60-80)$ & $80(70-110)$ & $0,000^{*}$ \\
\hline $\mathrm{GDP}(\mathrm{mg} / \mathrm{dL})^{*}$ & $99(62-118)$ & $190(109-465)$ & $0,000^{*}$ \\
\hline
\end{tabular}

Data is reported as a number (\%) and median (minimum-maximum), data taken from the normality test using the ShapiroWilk test after transformation data, data is still not normal, "Mann-Whitney test, p value <0.05: different meaningful. BMI: body mass index. GDP: fasting blood glucose.

Observation of plasma MDA levels between groups aims to see differences in the status of oxidative stress in the body of each group under conditions of hyperglycemia. MDA levels were measured using themethod thiobarbituric acid reactive substances (TBARS), which was analyzed statistically using the Mann-Whitney test. MDA levels were found to be higher in the case group (DMT2) than in the control group (Non-DM). When compared to MDA levels between control subjects and T2DM patients, statistically significant differences were obtained (value $p>0.00$ ). Comparison of MDA levels of the two groups can be seen in Table 2.

Table 2. Differences in the levels of MDA ( $\mathrm{mol} / \mathrm{L})$ between

\begin{tabular}{llll}
\hline & Group & $\begin{array}{c}\text { Median } \\
\text { (minimum-maximum) }\end{array}$ & value $p$ \\
\hline MDA (mol / L) & $\begin{array}{l}\text { Controls }(\mathrm{n}=50) \\
\text { Type 2 diabetes }(\mathrm{n}= \\
\text { 50) }\end{array}$ & $\begin{array}{l}1,69(41-4,16) \\
2,4(52-43,43)\end{array}$ & $0,000^{*}$ \\
\hline "Mann-Whitney Test & &
\end{tabular}

Frequency distribution of MDA levels in cases was MDA Normal (24\%) and Normal MDA (6\%), whereas in controls the MDA was Normal (26\%) and MDA Normal (44\%) . There were significant differences in MDA frequency distribution between cases and controls ( $p=0,000)$.test results Odds ratio to determine the risk of abnormal MDA levels showed significant differences between cases and controls ( $p=0,000$, OR 6.77 95\% CI 2.44-18.73). The value of obtained Significancy 0.001 is which shows that the correlation between the levels of GDP and MDA in this study is statistically significant.correlation value Spearman of 0.340 indicates that the direction of positive correlation with the strength of weak correlation. Table. 3 presents the results of thecorrelation analysis Spearman. The table consists of the correlation coefficient (r), p value, number of subjects. 
Table 3. Spearman CorrelationTest Results

\begin{tabular}{lccc}
\hline Variable & & GDP \\
\hline MDA & $\mathrm{r}$ & 0.340 \\
& $p$ & 0.001 \\
& $\mathrm{n}$ & 100 \\
\hline
\end{tabular}

${ }^{*}$ Spearman correlation test

\section{Discussion}

Hyperglycemia in T2DM can cause individuals to experience oxidative stress due to an increase in free radicals of reactive oxygen species (ROS) produced through glucose autoxidation pathways, nonenzymatic glycation of proteins, polyol pathways, glycolysis pathways and pentose phosphate pathways, accompanied by decreased antioxidant activity in protecting cellular components against ROS attacks. ${ }^{23-25}$

Epidemiological studies and experiments show that an increase in ROS has implications for lipid peroxidation. ${ }^{26}$ ROS compounds cause oxidative damage by attacking two or more double bonds of membrane lipid components to complement electrons. ${ }^{27-29}$ In the propagation stage, ROS oxidized lipid components can produce malondialdehyde (MDA). ${ }^{30}$ ROS compounds are reactive so their measurements are very difficult to apply directly. ${ }^{31}$ Therefore, checking MDA levels can be used as a marker Oxidative stress that can indirectly describe the effects of ROS.

The results showed that MDA levels were higher in T2DM patients compared to the control group and had a risk of 6.77 times an increase in MDA in the event of hypeglycemia in patients with T2DM ( $p=0.000$, OR 6.77 CI 95\% 2.44-18.73) . Increased MDA levels indicate oxidative stress caused by increased ROS activity which causes peroxidation in the cellular membrane lipid components. Research on MDA examination in patients with T2DM has been done, especially in some countries that have the highest prevalence of diabetes, namely (1) China, Chen et al. (2012) found DMT2 serum MDA levels (3.69 $\pm 0.39 \mu \mathrm{mol} / \mathrm{L})$ higher than controls $(2.87 \pm 0.63 \mu \mathrm{mol} / \mathrm{L})$ with $\mathrm{p}<0.01$; (2) India, Khemka et al. (2014) found serum MDA levels were significantly higher in non-obese T2DM $(3.21 \pm 1.84 \mathrm{nmol} /$ L) than controls $(2.05 \pm 0.99 \mathrm{nmol} / \mathrm{L})$ with $p<0.0001$; (3) Mexico, Jimenez-Osorio et al. (2014) obtained plasma MDA levels of T2DM patients without controlled glucose $(3.5 \pm 1.5$ $\mu \mathrm{M})$ higher than those with controlled glucose control $(3.07 \pm 1.5 \mu \mathrm{M})$ with $\mathrm{p}<0.05 .{ }^{32-34}$ 
ISSN 25980580

The difference in MDA concentrations reported in various results of the study was due to the influence of several factors. Some of these factors are the inclusion and exclusion criteria set by each researcher, the use of research methods and the results of examinations expressed for MDA examination are also different, accompanied by the geographical, socioeconomic and ethnic locations of each country that influence the subject's lifestyle.

In this study shows the correlation between the level of GDP and MDA is statistically significant with the direction of positive correlation. This is the same as the opinion of Farhan (2015) that MDA and hyperglycemia is a relationship that describes the progression of the disease and the development of chronic complications in DM based on the correlation between MDA levels and fasting glucose. This is because MDA plays an active role in the onset or progression of atherosclerosis related to abnormalities of lipid metabolism, so regulation of blood glucose is a very important factor to reduce or prevent the formation of lipid peroxidation in T2DM patients which may delay the progression of $\mathrm{DM}$ complications. ${ }^{35}$

Epidemiological studies and experiments show that an increase in ROS has implications for lipid peroxidation, which causes MDA accumulation to increase, and can be exacerbated by a decrease in the efficiency of antioxidant defense mechanisms in DM. Therefore, MDA levels are reported to be significantly increased in T2DM patients, and are among the oxidants known to be associated with T2DM complications. ${ }^{36}$

ROS reactions with polyunsaturated fatty acids (PUFA) from the membrane lipid component produce several aldehyde formations, including MDA. Malondialdehyde is a membrane lipid degradation product that is used as a marker of lipid peroxidation in T2DM. $\mathrm{T} 2 \mathrm{DM}$ is also known to be one of the diseases associated with inflammatory conditions. Inflammatory signal activation is characterized by increased synthesis of TNF- $\alpha$, IL-1, and IL-6, collectively called proinflammatory cytokines. Cytokines are produced through the JOS, NFKB, and PKC pathways mediated by ROS and the MDA effect. MDA levels in serum, plasma or saliva are also reported to be associated with several diseases and pathologies including inflammatory conditions through the generation of ROS. ${ }^{37}$

The imbalance ratio between increased production of ROS levels and disruption of antioxidant defense system activity is known to cause oxidative stress in individuals with DMT2 due to hyperglycemia. Oxidative stress causes inflammation via other pathways involving the activation of mediators of $c$-jun $N$-terminal kinase (JNK), nuclearfactor- $\kappa B$ $(\mathrm{NF}-\mathrm{kB})$, and protein kinase $C(\mathrm{PKC})$, which then trigger or worsen insulin resistance and lead damage and apoptosiscells $\beta$ of pancreatic. ROS exposure to this mediator causes 
ISSN 25980580

activation and increased expression of proinflammatory cytokines (IL-6) which are increased in T2DM patients. Increased Malondealdehyde (MDA) production also has the potential to activate CCP which is involved in the release of proinflammatory cytokines. Increased proinflammatory cytokines stimulate the synthesis of acute phase proteins in the liver, including C-Reactive Protein (CRP), $\alpha$-1-antitrypsin, haptoglobin, and fibrinogen. Inflammation is the body's defense mechanism from danger and repairs damage and disturbances caused by the danger. Patients with T2DM are very closely related to complications that result in inflammation or inflammation. ${ }^{38-40}$

\section{Conclusion}

From the results of the study it can be concluded that Malondialdehyde in T2DM subjects as Oxidative Stress Markers in Bengkulu with a risk of 6.77 times an increase in MDA levels compared to Non-T2DM subjects.

\section{Acknowledgement}

The authors are grateful to the Bengkulu Ministry of Health Poltekkes, the Indonesian BPSDMK Indonesia for providing valuable assistance for this research.

\section{References}

1. Agrawal, NK and Kant, S. (2014) 'Targeting Diabetes Infections: Newer Therapeutic Options', World J Diabetes. Published by Baishideng Publishing Group Inc., 8226 Regency Drive, Pleasanton, CA 94588, USA, 5 (5), pp. 697-710.

2. Ali, LA, Ali, DM, Mahdi, AG, 2015. Serial Sialic Acid in Non-Insulin Dependent Diabetic Mellitus Patients with Microvascular Complications. J. Appl. Chem. 4 (1): 154-159.

3. American Diabetes Association, 2017. Standards of medical care in diabetes-2014. He b. Care. 37 Suppl 1: 14-80.

4. Badawi, A., Klip, A., Haddad, P., Cole, DE, Bailo, BG, El-Sohemy, A. and Karmali, M. (2010) 'Type 2 diabetes mellitus and inflammation: Prospects for biomarkers of risk and nutritional intervention ', Diabetes Metab Syndr Obes, 3, pp. 173-186.

5. Bakhtiari, N., Hosseinkhani, S., Larijani, B., Mohajeri-Tehrani, MR and Fallah, A. 
ISSN 25980580

(2012) 'Red blood cell ATP / ADP \& nitric oxide: The best vasodilators in diabetic patients', Journal of Diabetes \& Metabolic Disorders. BioMed Central, 11 (1), p. 1.

6. Health Research and Development Agency (2013) 'Basic Health Research (RISKESDAS) 2013', National Report 2013, pp. 1-384. doi: December 1, 2013.

7. Bhattacharjee, D., Bhattacharya, GC, Chakroborti, G. and Ravi, B. V (2015) 'Study of Serial Sialic Acid and Copper as Inflammatory Markers in Type 2 Diabetes Mellitus.'

8. Bhutia, Y., Ghosh, A., Sherpa, ML, Pal, R. and Mohanta, PK (2011) 'Serum malondialdehyde level: Surrogate stress marker in the Sikkimese diabetics', Journal of Natural Science, Biology and Medicine. Medknow Publications, 2 (1), p. 107.

9. Birben, E., Sahiner, UM, Sackesen, C., Erzurum, S., Kalayci, O., 2012. Oxidative Stress and Antioxidant Defense. JW Allerg. Org. : 1-19.

10. Cangemi, C., Skov, V., Poulsen, MK, Funder, J., Twal, WO, Gall, M.AA., Hjortdal, V., Jespersen, ML, Kruse, TA and Aagard, J. (2011 ) 'Fibulin-1 is a marker for arterial extracellular matrix alterations in type 2 diabetes', Clinical chemistry. Am Assoc Clin Chem, 57 (11), pp. 1556-1565.

11. Cao, B., Liu, J., Qin, G., Tian, S., 2012. Oxidative Stress Acts on Special Membrane Proteins To Reduce the Viability of Pseudomonas Syringaepvtomato. J. Proteom. Res.11: 4927-4938.

12. Cariello, A., Testa, R., 2009. Antioxidant Anti-Inflammatory Treatment in Type 2 Diabetes. He b. Care. 32 (2suppl): 232S-236S.

13. ChenSC., SongGY., SunY,Liu N,.2012. The relationship between oxidative stress and endothelial progenitor cells counts in the first-degree relatives of diabetes mellitus. Zhonghua Nei Ke Za Zhi, 51 (3): 197-200.

14. Corwin, EJ, 2009. Nutrition, Elimination, Function and Dysfunction. In: Yudha, EK, Wahyuningsih, E., Yulianti, D., Karyuni, PE (Eds.): Pathophysiology Pocket Book, Ed. 3, pp: 622-628 EGC, Jakarta.

15. Dave, A., Kalra, P., Gowda, BHR, Krishnaswamy, M., 2015. Association of Bilirubin and Malondialdehyde Levels with Retinopathy in Type 2 Diabetes Mellitus. Ind. J. Endoc. Metab. 19 (3): 373-377.

16. Defronzo, RA, Eldor, R., Abdhul-Ghani, M., 2013. Pathophysiologic Approach to Therapy in Patients with Newly Diagnosed Type 2 Diabetes. He b. Care 36 (2 Suppl): 127S-138S.

17. Divija, DA, Rajeshwari, A., Nusrtah, A., 2013. Evaluation of Serum Sialic Acid and Microalbuminuria in Diabetic Nephropathy. Int. J. Rec. Trend. Sci. Tech. 3 (8): 219- 
223.

18. El Hansi, NMSM, 2007. Protective Role of Grape Seed Extract Against the Effect of Electromagnetic Radiation on Retinal Rhodopsin [Thesis]. University of Ain Shams, Egypt (EG).

19. Erdogan, HM, Karapehlivan, M., Citil, M., Atakis, O., Uzlu, E., Unver, A., 2008. Serum Sialic Acid and Oxidative Stress Parameters Changes in Cattle with Leptospirosis. Vet. Res. Commun. 32: 333-339.

20. Forbes, JM, and Cooper, ME, 2013. Mechanism of Diabetic Complications. Physiol. Rev. 93: $137-188$

21. Frohnert, BI, Bernlohr, DA, 2013. Protein Carbonylation, Mitochondrial Dysfunction, and Insulin Resistance. Adv. Nutr. 4: 157-163.

22. Guo, L., Chen, Z., Amarnath, V., Davies, SS, 2012. Identification of Novel Bioactive Aldehyde-modified Phosphatidylethanolamines Formed by Lipid Peroxidation. Free Radic. Biol. Med. 53 (6): 1226-1238.

23. IDF (2015) IDFIDF Diabetes Atlas, Diabetes Atlas. doi: 2-930229-80-2.

24. Jayasekharan, VP, Ramya, R., Rajkumar, K., Kumar, TD, Nandhini, G., Kumar, SS, 2014. Estimation of Nitric Oxide and Malondialdehyde in Serum and Saliva of Patients with Oral Lichen Planus. J. Res. in Dental Sci. 5 (4): 230-236.

25. Jetawattana, S. 2005. Malondialdehyde (MDA), A Lipid Oxidation Product [paper]. Free Radicals in Biology and Medicine, pp: 222-77. UNIV. of Lowa, Lowa City (IA).

26. Jozwik, M., Wolczynski, S., Jozwik, M., Szamatowicz, M., 1999. Oxidative Stress Markers in Preovulatory Follicular Fluid in Humans. Mole. Hum. Repro. 5 (5): 409413.

27. Khan, MWA, Banga, K., Khan, WA, 2012. Gluco-Oxidation of Proteins in the Etiology of Diabetic Retinopathy. In: Ola, MS (Ed.): Diabetic Retinopathy, InTech : $31-52$.

28. Kostova, V., Antonova, N., Velcheva, I., Ivanov, I., 2012. Comparative Analysis of the Rheological Properties of Blood in Patients with Type 2 Diabetes. Ser. Biomecha. 27 (3-4): 80-85.

29. Kumawat, M., Sharma, TK, Singh, I., Singh, N., Ghalaut, VS, Vardey, SK, Shankar, V., 2013. Antioxidant Enzymes and Lipids Peroxidation in Type 2 Diabetes Mellitus Patients with and without Nephropathy. North Am. J. Med. Sci. 5 (3): 213- 219.

30. Kumawat, M., Sharma, TK, Singh, I., Singh, N., Ghalaut, VS, Vardey, SK, Shankar, V., 2013. Antioxidant Enzymes and Lipids Peroxidation in Type 2 Diabetes Mellitus 
Patients with and without Nephropathy. North Am. J. Med. Sci. 5 (3): 213- 219.

31. Kundu, D., Roy, A., Mandal, T., Bandyopadhyay, U., Ghosh, E., Ray, D., 2013. Relations of Iron Stores to Oxidative Stress in Type 2 Diabetes. Nig. J. Clin. Practice. 16 (1): 100-103.

32. Kurtul, N., Gokpinar, E., 2012. Salivary Lipid Peroxidation and Total Sialic Acid Levels in Smokers and Smokeless Tobacco Users as Maras Powder. Med. Inflam. : 18.

33. Kutmon, M., Evelo, CT, Coort, SL, 2014. A Network Biology Workflow to Transcriptomics Study Data of The Diabetic Liver. BMC Genome. 5: 971-981.

34. Li, Z., Gang, Ya-Na., Jiang, Jian-Dong., Kong, Wei-Jia., 2014. Antioxidant and AntiInflammatory Activities of Berberine in the Treatment of Diabetes Mellitus. EviBased Comp. Alter. Med. : 1-12.

35. Likidlilid, A., Patchanans, N., Peerapatdit, T., Sriratanasathavorn, C., 2010. Lipid Peroxidation and Antioxidant Enzyme Activities in Erythrocytes of Type 2 Diabetic Patients. J. Med. Assoc. Thai. 93 (6): 682-93.

36. Lodgotra, A., Verma, P. and Raj, SS (2016) 'Estimation of salivary and serum biomarkers in diabetes and non-diabetic patients - A comparative study', Journal of Clinical and Diagnostic Research, 10 (6), p. ZC56-ZC61. doi: 10.7860 / JCDR / 2016 / 19135.7995.

37. Marchitti, SA, Brocker, C., Stagos, D., Vasiliou, V., 2008. Non-P450 Aldehyde Oxidizing Enzymes: The Aldehyde Dehydrogenase Superfamily. Expert Opin Drug Metab. Toxicol. 4 (6): 697-720.

38. McCaskill, ML, Kharbanda, KK, Tuma, DJ, Reynolds, J., DeVasure, J., Sisson, JH, Wyatt, TA, 2011. Hybrid Malondialdehyde and Acetaldehyde Protein Form adducts in the Lungs of Mice Exposed to Alcohol and Cigarette Smoke. Alc. Clin. Exp. Res. 35 (6): 1106-1113.

39. McDonagh, EM, Bautista, JM, Youngster, I., Altman, RB, Klein, TE, 2013. PharmGKB Summary: Methylene Blue Pathway. Pharmacogen. Genomics. 23 (9): 498-508.

40. Mohamed, J., Shing, SW, Idris, MHM, Budin, SB, Zainalabidin, S., 2013. The Protective Effect of Aqueous Extracts of Roselle (Hibiscus Sabdariffa. UKMR-2) Against Red Blood Cell Membrane Oxidative Stress in Rats with StreptozotocinInduced Diabetes. Clinics. 68 (10): 1358-1363. 
ISSN 25980580 